\title{
Chapter 2 \\ Water Ethics - Orientation for Water Conflicts \\ as Part of Inter- and Transdisciplinary \\ Deliberation
}

\section{Armin Grunwald}

\begin{abstract}
The notion of a water ethics has only emerged over the past 10 years. It is mainly motivated by environmental concerns and the observation of water conflicts. This chapter focuses on the ethical aspects of human interventions into water systems. It describes cultural, moral and religious attitudes towards water and reviews the state of the art in this field. Its main objective is to conceptualise water ethics on the basis of the philosophical approach of discourse ethics and to draw conclusions for ethically responsible interventions into water systems and for dealing reasonably with water conflicts. Far from promising "miracles" from water ethics, the specific added value of ethical considerations lies in providing the orientation for ongoing debates on water challenges by not only applying substantial principles, but by offering suitable procedures as well.
\end{abstract}

Keywords Water ethics $\bullet$ Value of water $\bullet$ Sustainable development $\bullet$ Environmental justice $\bullet$ Equity $\bullet$ Responsibility $\bullet$ Western World $\bullet$ Islam $\bullet$ Christianity $\bullet$ Human right to water and sanitation

\subsection{Objectives and Approach}

The aim of water ethics is directed at responding to different challenges which have become obvious over the last decades: conflicts of interest in using scarce water resources, creeping river, sea and ocean pollution, devastating human interventions into sensitive water systems (drying-up of the Aral Sea and the Dead Sea as dramatic examples). These challenges have arisen out of human interventions into water cycles, to human changes of the chemical composition of waters by various forms of private and industrial use of water, and to human interventions into natural landscapes. The

\footnotetext{
A. Grunwald $(\bowtie)$

Institute for Technology Assessment and Systems Analysis (ITAS),

P.O. Box 3640, 76021 Karlsruhe, Germany

e-mail: armin.grunwald@kit.edu
} 
"human factor" in water systems is at the core of ethical considerations. It focuses on the impact of human interventions and consequences of this impact, assesses these interventions with respect to ethical criteria and explores the options for developing this human factor into a more responsible direction.

The notion of a water ethics has emerged over the past 10 years only and is still relatively unknown in the field of applied ethics. The extent of its body of literature is rather small up to now. It consists of a heterogeneous set of approaches to the value of water in different respects (cultural, religious, ecological and economical) and associated with the debates on sustainable development and environmental justice. To present, the largest part of water ethics has been motivated by environmental concerns and related to the field of environmental ethics.

This chapter focuses on the ethical aspects of human interventions into water systems. And with the following objectives it intends to:

- Describe cultural, moral and religious attitudes on and perceptions of the field of water, in particular, value assigned to water

- Review the state of the art in the field of water ethics and provide an overview and orientation of not only basic diagnoses, argumentation patterns, proposed solutions, but also of shortcomings and criticisms

- Conceptualise water ethics on the basis of the philosophical approach of discourse ethics (Habermas 1991) for providing orientation on how to identify responsible strategies for dealing with water challenges

- Categorise the field of water conflicts with respect to ethically relevant criteria and provide pointers on how to deal with those conflicts reasonably and responsibly

The overview provided, the proposal for water ethics developed, and the conclusions given towards possible contributions to solving water conflicts constitute a theory-based approach to water ethics. It shows that society cannot expect "miracles" from water ethics. Rather, the specific added value of ethical considerations lies in providing the orientation for ongoing debates on water challenges by not only applying substantial principles, but by offering suitable procedures as well. In order to exploit these benefits, ethical inquiries in the field of water must be embedded into inter- and trans-disciplinary approaches bringing scientific disciplines together with stakeholders, decision-makers and citizens in the regions under consideration.

\subsection{The Value of Water in Different Cultures}

Water as a crucial precondition of life has gained prominent importance in almost all cultures and religions. High value is assigned to water, in particular in regions with high scarcity of water, is often accompanied by strong commandments on its usage. In describing briefly the most relevant cultural attitudes towards water I do not follow the usual classification where Christianity is mostly identified with the Western World. Instead, I will argue that the modern attitude to water in the 
Western World developed its own and predominantly economic perspective while the water-related values of Christianity are closely related to those of Judaism and Islam. The case studies presented in this volume do not affect regions dominated by Eastern Asian religions I will focus in this section on the monotheistic religions and Western Modernity.

\subsubsection{Judaism, Christianity, and Islam}

The three monotheistic religions going back to Abraham and Moses, Judaism, Christianity and Islam, share common roots not only in spiritual respect. They all have their roots in areas with a harsh desert climate and water scarcity: Arabia, the Near East and Saharan North Africa. Not surprisingly, high value is assigned to water by all of them. The Bible in its Old and New Testament and the Quran are full of symbols related with water, pointing to water as source of life, or using analogies with water as metaphors for spiritual messages.

There are only a few indicators in the Bible on environment protection. Usually, the story of the Genesis is understood not only as permission, but even a commandment to humans to dominate nature: "Be fruitful, and multiply, and replenish the earth, and subdue it; and have dominion over the fish of the sea, over the fowl of the air, and over everything living thing that moveth upon the earth" (Genesis 1:28). However, it has often been stated that simplified criticism misses the point (Armstrong and Armstrong 2005). Rejecting the assignment of an eigenvalue to nature and considering the value of nature only in relation to human needs is clearly an anthropocentric perspective, but does not allow or even request careless dominion of waters and nature in general (Bartholomew I Ecumenical Patriarch of Constantinople 2010). In contemporary Christianity caring for water resources is seen as part of the duty of stewardship of nature (Pradhan and Meinzen-Dick 2010, p. 48). In Judaism, the Talmud perspective on the environment states that while we may use the world for our own needs, we may never irresponsibly damage or destroy the environment.

In Islam, in particular, water is a pivotal issue (Faruqui et al 2001). Scarcity has always influenced the perception of water by Muslims, and it has, accordingly, shaped their behaviour and customs. The water of rain, rivers and fountains is seen, against this experience, as a symbol of Allah's benevolence: "He sends down saving rain for them when they have lost all hope and spreads abroad His mercy" (Quran 25:48). Water is considered a gift from Allah and should be freely available to all. Any Muslim who withholds unneeded water sins against God: "No one can refuse surplus water without sinning against God and against man." That means that "true Muslim believers cannot grab water in excess to their needs since they are obliged to allow free access to any amounts of water beyond these needs" (Al-Awar et al. 2010, p. 32). Every human being, not only Muslim, is given right to drink to assure survival. There is a right of irrigation but domestic use has precedence over agricultural or industrial use. 
Regarding water radically as a common good makes it difficult to assign monetary value to it: following Islam, water should neither be bought nor sold (Al-Awar et al. 2010, p. 33). But how could then a water supply infrastructure be implemented at all? The solution to this problem is that "in spite of its original nature as common good, individuals have the right to use, sell, and recover value-added costs of infrastructure for water supply services" (Al-Awar et al. 2010, p. 33). This means that water belongs to the community and no one is allowed to own it unless labour was provided or an effort was taken to make it usable, or to distribute it. This does not create a right of ownership over water, but rather creates a property on the value added to water by labour, thus enabling pricing and trade (Gilli 2004).

\subsubsection{Western Modernity}

The capitalist economic system, which has developed over the past two centuries, has resulted in a materialistic culture. Value has been understood as monetary value to an increasing extent. Determining the monetary value of products and services is usually left to the rules of the marketplace: in the interplay between offer and demand, the adequate price will emerge. The "invisible hand" (Adam Smith) in the back of the participants at the marketplace will then take care that, if all participants will go for maximum profit for themselves, the collective will arrive at the optimal outcome. The reference of value determination is no longer an external authority such as nature, God or a holy book but economy. In the assignment of value to water this means: "Water has an economic value in all its competing uses and should be recognised as an economic good" (Young et al. 1994, p. 4).

Key to the economic view of water is demarcating it as a "resource". Classical economy understands nature as an ensemble of resources for human use: land, raw materials, minerals, biodiversity - and water. It was the U.S. American geographer and secretary of the U.S. Inland Waterways Commission, William McGee, who made this point in a famous paper (1909) expressing very clearly (and early) Western thinking about water as an economic resource which could and should be managed. In modern word this reads: "Managing water as an economic good is an important way of achieving efficient and equitable use, and of encouraging conservation and protection of water resources" (Young et al. 1994, p. 4).

But this is not the whole story. Already McGee and the community he worked with were also open to communitarian ideas and participation in the field of water (Schmidt and Shrubsole 2013), based on the conviction "that all the water belongs to the people" (McGee 1911, p. 822). Thus it becomes clear that Western Modernity is two-fold with an inherent tension: on the one hand, it reduces the value of water to that of an economic resource, but on the other it also acknowledged that water has a political and democratic side (which may be taken as a predecessor of the "human right on water" declared by the United Nations (UN) in 2010, see below).

This leads to the discussion on the common good-property of water in the Western World (Ostrom et al. 2003; Trawick 2010). For a long time, the supply of water was 
seen as task of public services. Large water supply and sewage infrastructures were built by municipalities and states. The value behind this is the public good property of water transformed into the state's duty to provide access to water and sanitation to everybody. However, neoliberal trends from the 1980s on have led to giving more emphasis to issues such as deregulation and liberalisation even in the field of water supply. In some countries, the borderline between state competencies and market affairs has been shifted in favour of the latter, expressing a shift in regarding the value of water towards an economic product. The installation of the human right on water by the UN in 2010 (see below) might be regarded as a counter-movement refocusing on the common good character of water. A permanent balancing process is required between considering water either as a common or a private good.

\subsubsection{The Need for Water Ethics Beyond Value Assignment}

Thus, value assignments to water are an essential element of important religions and cultures. However, they are of limited use only when facing modern challenges to water systems. Given the arguments below, water ethics must go beyond traditional value assignments.

The first argument is that all the value assignments given in cultures and religions are, in spite of the fact that they may include wisdom and reflect cultural experience, in some way "out of the sky". Their reference often is a holy book such as the Bible, the Talmud or the Quran. The statements on water given there are binding only for members of the respective cultures, traditions and religions. Regarding water as a gift of Allah and following all the consequences for dealing with water given in the Quran and the Sharia is binding only for Muslims, and similar with all other religious wisdom and commandment. The limited range of validity of those value assignments also limits the applicability to solve real-world problems in the modern, pluralistic and secular world.

The second argument is closely related to this. Value assignments may be contested and controversial among different cultural groups (Priscoli Delli et al 2004). In particular, cultural and religious values assigned to water do not help in solving water challenges crossing cultural and religious borders. Cultural and religious values may provide inter-cultural and inter-religious conflicts with valuable insight but cannot be a self-evident basis for conflict resolution. For example, in case of a water conflict, for instance between Islamic tradition and the Western capitalist approach, neither Quran nor neoliberal rules of the market have priority per se. Both value systems depend on particular normative convictions. Dealing with inter-religious and inter-cultural water conflicts needs a third perspective - and the promise of philosophical ethics is to provide such a perspective by grounding its argumentation not in particular tradition but rather in an argumentation claiming a more general validity. In case of conflict, ethics must question the values at place and look beyond. It cannot take religiously motivated value assignments to water as granted but has to scrutinise the normative bases and resulting rules for human behaviour with respect to their argumentative validity. 
A third argument focuses on strong limitations of value assignments for meeting major water challenges even within the same culture. For example, the Asian cultures express deep respect of water for life in general in highly abstract philosophical terms. While these may allow for a deeper understanding of water, life and nature, they will usually not be helpful in solving specific water conflicts, in orientating a more efficient use of water facing scarcity, and in deriving priorities in case of competing usage demands. Also a statement of the kind "Water offers a medium for creating a culture of peace" (Young et al. 1994, p. 4) is not helpful in spite of its truth: the opposite case could happen as well, and water could give rise to conflict instead to peace. The problem with high expectations on value assignments is that they are vague and not operable for specific contexts. They even do not prevent conflict in a morally homogeneous culture or religion. Conflicts of crude interest may occur between members of the same cultural or religious community. Then, obviously, the value assignments cannot help at all because all of the conflicting actors will share the same values. For example, some of the classical water conflicts in the Near East occurred between Islamic states (Iraq, Turkey, Syria, Jordan).

Summing up it becomes clear that the value dimension of water has to be considered carefully in water ethics because of its relevance to cultural attitudes to and perceptions of water. However, values assigned by religions, cultures and traditions are particular and not per se ethically legitimate, can often not prevent conflicts or orientate conflict resolution but have to be critically scrutinised with respect to their argumentative grounding. Situations in which existing values do not suffice to orientate action (e.g. in the case of conflicts between different value systems) shall be denoted as situations showing normative uncertainty. Ethics has developed exactly to facilitate coping by argumentation with such situations (Gethmann and Sander 1999).

\subsection{Water Ethics}

Based on a brief and critical review on existing literature on water ethics and a reflection on the very subject of any water ethics, the basic approach will be developed and structured into a substantial and a procedural branch. The section is completed by considerations on the precondition of this approach being applicable.

\subsubsection{Review of the Literature on Water Ethics}

The body of literature on water ethics is rather small and heterogeneous in terms of the ethics approach chosen. A first bundle of papers take the value of water in different cultural and religious respects into consideration (e.g. Priscoli Delli et al. 2004; UNESCO 2011). Most of the pieces on water ethics explain the demand for developing and implementing such an ethics. High expectations are raised such as: 
In short, we need a water ethic - a guide to tight conduct on the face of complex decisions about natural systems we do not and cannot fully understand (Postel 2010, p. 222).

Poul Harremoës (2002) expects that a water ethics - in his understanding a more responsible and reflected behaviour of water users orientated to the precautionary principle - would make over-regulation by the state unnecessary. Most of the approaches, however, assume in broader sense that a water ethics shall help to protect and conserve water systems as the basis of present - and even more - future life on Earth. The call for a new water ethics expresses far-ranging concerns about increasing degradation of water systems - and is an indicator of severe dissatisfaction with protection measures implemented so far and also with our decision-making capabilities on water issues today.

The largest part of water ethics until the present has been related to the field of environmental ethics. An early and influential work by the U.S. American ecologist Aldo Leopold (1949) postulating a "land ethic" was the point of departure. His motivation was to develop a new type of ethic, where the boundaries of the communities shall be extended from humans to include soils, waters, plants and animals (Priscoli Delli et al. 2004, p. 9). Armstrong (2006; 2009) used this postulate as template to develop a water ethic and reasoned:

A thing is right if it preserves or enhances the ability of the water within the ecosystem to sustain life; and wrong if it decreases that ability (Armstrong 2006, p. 13).

However, also the reference to life as such or to "each organism" might not be very helpful because measures usually support some forms of life but would threaten others. The life as such cannot be sustained - only specific forms of life (ecosystems, organisms etc.). Therefore, additional criteria would be required to allow for the determination of priorities. Armstrong, however, refuses to start this debate. This is indeed the most acrimonious question of any water ethics, which has to deal with such typical conflicts, ambiguities or even dilemmas. There is no simple way to "sustain life" but we have to ask questions such as "sustain what life under which circumstances and at what price?"

Some authors look for an overall answer to this question in the direction of ranking the value of the natural principally higher than the value of the artificial. Human intervention, in this perspective, only can diminish the value of nature. Even the image of nature restoration is bad because it is human intervention. Statements of the kind

The ethical principle of stewardship teaches respect for creation and moral responsibility for that creation. However, it also calls for wise use of creation and complete unwillingness to modify nature (Priscoli Delli et al. 2004, p. 16).

express a romantic picture and ignore completely that "complete unwillingness to modify nature" is a strange postulate looking at the reality of human intervention into nature. Instead of a "complete unwillingness to modify nature" we need the willingness to take responsibility for our modifications of nature and to act accordingly. The valid question of water ethics is not how to sustain life (Armstrong above) and to leave nature untouched but is for the responsibility of human intervention into water systems. 
Also other work in the context of water ethics supports this "anthropocentric turn" and the rejection of romantic eco-belief. In particular, considerations of water systems under the postulate of sustainable development (e.g. Parodi 2008; Lehn and Parodi 2009) have unavoidably an anthropocentric focus because they are dealing with human needs today and in future (WCED 1987; Grunwald and Kopfmüller 2012). In order to avoid misunderstanding: "anthropocentric" in this sense does not imply taking the position of human dominion and complete control over nature. The point here only is that the sustainability focus on human needs rejects fundamental bio-centric positions (such as taken by Leopold 1949) and instead asks how to sustain ecosystems and their services and functions in order to sustain or improve the possibilities of meeting human needs today and in the future.

Some sets of ethical principles have been proposed for water ethics (Groenfeldt 2013). The UNESCO (2011, pp. 18ff) unfolds the normative dimension of water ethics along a number of principles stemming partially from law and partially from ethics:

- Principle of human dignity and the right to water

- Principle of equity in availability and applicability of water

- Principle of eco-centric ethics

- Principle of vicinity

- Principle of frugality

- Principle of transaction

- Principle of multiple and beneficial use of water

- Principle of mandatory application of quantity and quality measures

- Principle of compensation and user pays

- Principle of polluter pays

- Principle of participation

- Principle of equitable and reasonable utilisation

This list seems to be comprehensive but might be perceived as confusing and overladen. It could be used as a checklist to identify ethically relevant issues of a water challenge under consideration and might thus have a heuristic function. However, it is not clear in which way this list could be made operable to be used in processes of deliberation and decision-making. What is missing in this respect is a system of criteria of weighing these principles in case of conflict, and a procedural proposal how this could be done.

\subsubsection{Subjects of Water Ethics}

One of the major lessons learned when considering the existing work on water ethics is its subject. As has become clear the subject of water ethics is not - as many people might expect - "water" as such but is human intervention into water systems and cycles. Water itself is subject to life, to the economy, to religious thought and to cultural attitudes. Ethics, however, always considers options how to act or to decide. 
Human interventions into water systems and cycles (including the option not to intervene) are subject to water ethics (this picture puts water ethics in close neighbourhood to the ethics of technology (Parodi 2008; Potthast 2013).

Consequently, a differentiated typology of human interventions into water systems regarding criteria for ethical reflection would be required but is still desiderate. Rough characterisations would distinguish between intended and non-intended interventions. Intended interventions into water systems include direct measures such as building dams for different purposes, deviating rivers and the installation of huge irrigation systems, but also indirect measures regulating or de-regulating water trade and other elements of water governance. Non-intended interventions comprise of the side effects of human action resulting out of other actions. Examples are the creeping groundwater pollution by herbicides and antibiotics from medical and agricultural use, the heating of rivers by nuclear power plants or industry and the pollution of the oceans.

In a situation of normative uncertainty (see above) - for example: the planned regulation of a river leads to protest by ecologists; the planned construction of a hydroelectric power station is rejected by local people; water usage for irrigation in the upstream area of a river causes or increases scarcity of water in the downstream area - the task of ethical reflection is to analyse the normative foundations of the different and possibly conflicting options on the table to provide support in their assessment and comparison, and to contribute to deliberation and decision-making.

Water ethics thus involves a necessary anthropocentric perspective by looking at human intervention, intended or non-intended. Saying this may cause immediate protest by ecologists and sections of bio- and eco-ethics (e.g. Leopold 1949; Katz 1997; Armstrong 2006). Frequently, the anthropocentric perspective of former morals is blamed for negative developments in the natural environment we witness today: loss of biodiversity, climate change, pollution of waters, etc. Usually, other perspectives than an anthropocentric ethics are proposed to improve the situation, such as eco- or bio-centred ethics. However, the basis discourse model of philosophical ethics (Habermas 1991) cannot be other than anthropocentric because only humans can participate in discourse and deliberation. For example, animals or water systems cannot take the role of an active discourse partner. We humans have to take stewardship over them to bring their assumed "perspectives" into the ethical discourse. In this sense water ethics must also be anthropocentric - which, however, should not be confused with postulating for human dominion over nature. Issues of water protection in the interest of future generations, of maintaining biodiversity or of functioning eco-systems may be subject to this discourse as well as conflicts between upstream and downstream users. "Anthropocentric" means that it is up to us humans to take responsibility seriously - because, as far as we know, there is no other species on Earth able to do this. Thus, exploring and assessing options for taking over responsibility for water systems and water cycles by human interventions into water systems is the target of water ethics.

Because human intervention into water systems usually is done by implementing technologies (dams, river regulation, water distribution grids, irrigation 
technologies, geo-technologies, etc.) including their societal elements such as regulations, rules for action, acceptance patterns, the best place of water ethics in the system of applied ethics (Nida-Rümelin 2005) is, accordingly, the ethics of technology (Grunwald 2013) (with strong links with environmental ethics).

Beyond this water ethics is related also to philosophy of nature, with ethics in the field of the economy, with risk ethics and also with bio-ethics - and, of course, with the overall debate on sustainable development. Additionally, in an ethical discourse on water issues further groups of people must be involved: scientists (e.g. from geography, hydrology and engineering), social scientists (e.g. from cultural studies and economics) and, perhaps, humanities and cultural sciences bringing in knowledge about inter-cultural and inter-religious understanding. Furthermore, dealing with "real world" problems in an ethical discourse needs to involve groups and people affected, stakeholders and decision-makers etc. (see the principle of participatory water governance below).

\subsubsection{Substantial and Procedural Aspects of Water Ethics}

What we can learn from the existing papers on water ethics is that sets of principles might be used as checklists, e.g. to analyse water management options and to compare them. These principles express specific ideas, requirements and norms on how we currently imagine options of responsible interventions into water systems, or which types of interventions we would not consider responsible. They could be used to determine criteria of responsible action.

Those principles are "substantial" in a sense - they promise to provide guidance in cases of normative uncertainty. However, there are severe problems unanswered. First the question arises which system of principles we would like to adopt for what reasons. Second, those systems do not tell us how to proceed in cases of tension and trade-offs - and the experience shows that the field of sustainable development is full of them (Grunwald and Kopfmüller 2012). In the specific field of water it is easy to imagine conflicts, for example, between today's use of water and the assumed interests of future generations. Third, high uncertainties in the assessment of the consequences of today's actions for future water and ecosystem developments will prevent any fixed substantial system of principles from being helpful in the long run (Grunwald 2007). And fourth, any principles will remain abstract to the specific constellation of a given water conflict, while ideas for solutions to the conflicts always have to include contextual specificities and need participation of groups and persons affected (Schmidt and Shrubsole 2013).

Thus, the set of substantial principles has to be in a sense, flexible, must not be too strict and has to be complemented by added procedural elements. The combination of substantial and procedural elements allows the combination of providing orientation and being flexible and adaptive to specific situations.

Drawing on the literature on water ethics available (mainly UNESCO 2011; Groenfeldt 2013), the author would like to propose to use the following set of principles (closely related with the proposal made by Groenfeldt 2013) to be used in water ethics discourses as guiding heuristics: 


\subsubsection{Human Right to Water and Sanitation}

The Human Right to Water and Sanitation was declared by the UN in 2010 (UNESCO 2011). It mirrors the fact that access to water, as well as to sanitation, are necessary preconditions of human life. In a sense the right to water is an implication of the postulate of human dignity not only because water is necessary for survival but also because water is essential for food production, for energy and also for cultural issues. In ethical respect, a clear imperative follows to ensure the fulfilment of this right today and in the future. This principle closely relates to the debate on water as a common good and also allows reference to the value dimension of water, e.g. in Islam.

\subsubsection{Sustaining Ecosystem Functions}

Ecosystem functions are essential for a functioning natural environment - in the way of providing ecosystem services according to human needs and for "keeping nature alive" (Groenfeldt 2013) as well. This principle overlaps strongly with the intergenerational dimension of the imperative of sustainable development (Grunwald and Kopfmüller 2012), which calls for long-term responsibility in maintaining the natural conditions of human life (Jonas 1979). But it also includes other ecosystem functions such as cultural or religious ones, or aesthetic arguments (Ott 2010). The precautionary principle (Harremoës et al. 2002) also has its place here in face of the huge uncertainties in long-term developments of water systems.

\subsubsection{Responsible Use of Water}

The Human Right to Water is a right to use water. This use, however, is restricted by the other principles: the actual use of water has to be arranged in a way that (1) the future fulfilment of the right to water is not endangered and (2) ecosystem functions will be sustained. This normative situation may limit the industrial and agricultural use of water in specific cases. Facing high uncertainties concerning long-term effects of human interventions it might be a postulate of responsibility to take care of the resilience of water systems. Responsibility also includes caring about the safety of water engineering, e.g. in the construction of dams.

\subsubsection{Participatory Water Governance}

The principles given above do not allow direct derivation or deduction of ethically justified advice. On the one hand, this will be prevented frequently by the virulence of conflicts between the principles (e.g. the well-known conflict between the economic use and the common good character of water). The judgement with respect to one principle might be positive but negative to another one. On the other, the principles are rather abstract and must be "contextualised", i.e. made operable for specific 
cases. This is an issue of hermeneutics, interpretation, deliberation, balancing and weighing - a political activity in its wider sense. Theories of democracies as well as ethics postulate that these activities should be performed in a participatory manner, involving people concerned and affected, as well as taking into account future generations and ecosystems by applying an advocatory approach.

These principles are, due to ethical theory, universal. They serve as "regulative ideas" and shall orientate ethical deliberation. But they cannot be used for simply deducing the ethically best or optimal solution. The process of identification needs the "real deliberation" with people concerned and affected as well as with stakeholders and decision-makers (Schwemmer 1987). Assessing optional water interventions with regard to ethical criteria, and this is the "procedural" message of discourse ethics, should be arranged in accordance with principles of fairness and equity (see Habermas 1991; Renn and Webler 1998) including the requirements:

- Participants in communicative exchange are using the same linguistic expressions in the same way.

- Participants agree to modify their own positions in case of better arguments given by others.

- No relevant argument is suppressed or excluded by the participants.

- Everyone entitled to participate, and everyone is equally entitled to introduce new topics or express attitudes needs or desires.

- No force except that of the better argument is exerted.

- No validity claim is exempt in principle from critical evaluation in argumentation (this in particular also holds for religious belief).

Processing the discourse in this way produces its result - and there is no abbreviation available, no algorithm, which could "calculate" the result without the "real deliberation" in a discourse. Habermas' basic idea is that the validity of ethical advice cannot be justified by an isolated individual thinking about the world, or by deriving it from abstract principles in an "ivory tower". Instead, the validity of a normative statement can only be justified in processes of inter-subjective argumentation in the real world. Water ethics shows itself as a specific kind of discourse ethics on water management intervening into water systems.

If the argumentation itself shall provide valid normative statements the focus is shifted to the conditions and presuppositions of the discourse. Criteria must be given to ensure that in a discourse taking place in the real world, the conditions are fulfilled to allow the "power of the argument" only to determine its course. Misuse of the discourse for ideological purposes, persuasive speech instead of argumentation, asymmetric access to important knowledge and other exertions of power in contrast to argumentative power have to be excluded.

In a discourse on water issues arguments shall be exchanged, challenged and defended following strict rules of fairness and equity, which shall ensure the justice of the procedure. All people involved or affected have the same right to participate and to bring in their arguments. This approach applies both to the discourses on water use and to decision-making in water governance. 
Beyond considering these principles as regulative ideas to give orientation to ethical reflection, another function of these principles should be mentioned. They can also be used to educate and build capacity in the field of water as they include the main lines of argumentation in discussing any interventions into water systems. In this way the principles also could contribute to raising awareness about water problems, to avoid or overcome biased or limited views on those interventions, to enrich public debates and to shape a more responsible collective consciousness.

\subsection{Cultural and Social Preconditions of the Ethical Discourse}

The above-mentioned considerations raise the question how the preconditions of ethical discourses could be fulfilled - and what could be done in case they are not fulfilled. A sociological suspicion is that the idea of ethics is purely counterfactual in the sense that it might be an artefact without any empirical relevance: wishful thinking in an idealised world. However, things are more complex. The target of ethics - looking for an argument-based and peaceful way of conflict solving - is built on a strong normative foundation (Habermas 1991). It provides us with wellfounded ideas of how conflicts should be solved - and these ideas serve as a kind of benchmark against which we can evaluate our status quo situation. This comparison then can give rise to change in the status quo - in this respect the power of normative thinking can even be revolutionary.

However, the question remains how the fulfilment of the necessary preconditions of ethical discourses could be supported. Counteracting aspects are, obviously:

- Religious fundamentalism - in an ethical discourse every normative position must be subject to criticism and possible change which is incompatible to fundamentalism.

- Prejudice due to race, gender, culture, etc. - ethical discourses need mutual respect among the discourse partners including the conflicting opponents independent from racial, cultural or gender issues.

- Fundamentalist commitments to own and partisan positions without any willingness to modify them in case of better arguments in favour of other positions.

Looking at the empirical situation it quickly becomes clear that the preconditions of ethical discourses will mostly be not fulfilled. However, that is no forceful argument against ethical discourses raises the question how the fulfilment of such conditions could be supported. The challenge is to convince people to participate and to accept the rules of an ethical discourse. At the core of this challenge is to convince people to accept the "discourse risk" which means: you never know at the beginning of the discourse what the result will be - and possibly the result will be contradictory with your initial position. Why should people accept this risk? From an ethics 
point of view good arguments should be provided instead of psychologically trying to simply persuade people. And there are several arguments, in particular in the field of water:

- People usually understand that they are not alone in the world - solidarity is often a concern.

- In particular, solidarity in the field of water supply can be built on deep-ranging intuitions and on cultural traditions (e.g. in Islam), which recommend or even request not to endanger supplying water to other human beings.

- To be more specific, the very nature of water being a necessary precondition of (human) life is a very strong argument that could hinder actors in egoistically exploiting water resources at the expense of threatening other actors with too little water for living.

- In some cases, there might also be a utilitarian argument for ethical discourses: considering for example, upstream and downstream competition for using water resources it might be a good idea to identify possible win-win situations. Cooperation might open up added value for all the downstream and upstream regions in comparison to a purely competitive situation.

Besides providing good arguments for trying to solve conflict by means of ethical reasoning and discourse, it is essential to establish trust among the actors involved (Habermas 2008). To this end, cultural and value resources (see above) should be exploited to maximum extent. For example, it has been shown that Islamic tradition provides a lot of chances to mobilise and motivate people to think about the responsible use of water resources (Gilli 2004). Analogously, cultural resources and traditions should also be considered as a means of constructing adequate preconditions for ethical discourses.

The basic precondition of an ethical discourse is to respect other human beings as morally autonomous persons (Immanuel Kant). Thus, taking care about the preconditions of an ethical discourse on the usage of water is an issue to create insight by argumentative reasoning rather than trying to persuade people. Obviously, the expectability of creating insight by arguments depends on cultural issues and the status of education. Thus, at the end, it is an issue of education and capacity building that contribute in fulfilling the preconditions of an ethical discourse - at least from a mid and long-term perspective.

\subsection{Water Conflicts}

If all the principles identified above would be met simultaneously by specific water management strategies or other human interventions into water systems, there wouldn't be any problem in ethical respect. But usually there are counteracting influences, trade-offs and inherent conflicts. Meeting one or two of the principles frequently will endanger meeting the others. Normative uncertainties, in particular conflicts on the required priority-setting between competing claims and their 
justification, arise and are subject to ethical analysis and discourse. In making the ethical water discourse operable, a lot of concretisations and contextualisation must be applied, according to scales in space and time, but also with respect to different types of normative uncertainties to be tackled. A typology of water conflicts, of argumentation patterns used in specific constellations and of typical normative uncertainties involved would be desired. In this section, I would like to discuss briefly some typical conflicts arising in water systems interventions and ask for the possible contribution of ethics to deal constructively with them. Before doing this, the scope of possible conflict types shall be sketched.

Discourses around water have some specific properties related to the medium under consideration. Water and water systems are different from soils and other compartments of the environment. Water is almost always flowing: it passes landscapes and private property, soils and regions (e.g. see above for the Islamic view on this). It cannot be consumed chemically - in using water it remains the same compound of hydrogen and oxygen. However, human use of water adds other materials and chemicals and so usually leads to degradation of its quality, or it changes landscapes and impacts human settlements, ecosystems and the biodiversity.

Water conflicts have different origins and can be characterised by different parameters. An ethical characterisation would consider possible or intended interventions into water systems with a focus on questions such as:

- What is at stake? Are the aims of the intervention justified? Which non-intended effects could arise?

- Who or what would be the winners and losers (not only with respect to humans but also regarding elements of the biosphere and the natural environment in general)?

- Could rights (e.g. the Human Right on Water but also cultural or religious rights) be violated as unintentional side effects?

- What can be said about the distribution of gains and losses, of costs and benefits, of chances and risks among people alive today or between contemporary and future generations?

- Which uncertainties are involved, which characteristics do they show, and should the precautionary principle (Harremoës et al. 2002) or another type of precautious approach be applied?

- Which timescales are involved? There are huge differences in the timescales of the impact of human interventions in water systems and the recovery of the water systems. This is important in particular in taking over long-term responsibility

- Are there alternatives available to the intervention proposed meeting the same targets at lower "moral costs"?

Basically, the "moral constellation" of the water conflict under consideration must be clarified and then can be used for categorising different types of conflict. This constellation in particular will determine who and which positions should be represented in the ethical discourse. It also must be clarified whether advocates of non-human interests or of future generations should be present. 
This "moral constellation" strongly depends on the range of the conflict under consideration and its possible implications in space and time. Extension in space and time influences heavily the range of moral positions and of actors to be involved. A first and rough differentiation could be:

- Conflicts on the use of water in a strongly limited region without impacts beyond the borders of the region and beyond present time as well. In this case the actors from the corresponding region directly affected are entitled to solve the conflict according to ethical rules.

- Conflicts in a strongly limited area between the economic use of water and longterm ecological requests of sustaining ecosystems and biodiversity - in this case advocates of those desires must be included.

- Conflicts on the use of water today with assumed interests of future generations, e.g. in case of degrading water resources by usage or of degrading landscapes. In this case advocates of future generations must be included in the ethical discourse.

- Conflicts on large-scale interventions into water systems (geo-engineering Potthast 2013), which per se will have a global, an inter-cultural and an intertemporal dimension.

This approach can only demarcate the task in front of water ethics. In the literature available (see above), the task of classifying water conflicts in ethical respect has not even been touched. However, it is necessary to do so because it is exactly this type of differentiation that allows water ethics to become specific and to genuinely contribute to dealing rationally and responsibly with conflicts. In particular, this type of differentiation allows establishing relations between reflective ethics and the governance in the respective field. The ethical discourse as a "real deliberation" (see above) forms the link between theoretical ethical analysis and reflection on the one side, and empirical deliberation and decision-making on the other. This is also the place to locate debates on the assignment and distribution of responsibilities.

Classifying water conflicts is, in this sense, necessary to enable actors to determine adequate strategies in responding to challenges and involving stakeholders. However, the classification and subsequent assignments of an individual conflict to a classification scheme will be an act in itself, which is not value-neutral and might itself be an issue of controversy. Thus those determinations are part of the ethical discourse. This also might include reaching a consensus that the assignment usually will not fully meet all of the situational aspects but rather some of them, which have been identified crucial for problem-solving.

\subsection{Water Ethics and Specific Water Conflicts}

Water ethics is an emerging field of ethical reasoning. Its motivation is fuelled by high concerns about the stability of water cycles, about quality issues of water, about increasing water scarcity in many world regions, about an increasing pressure on 
water systems by agriculture and industry but also about growing population - shortly speaking: concerns about the sustainability of water systems and about possible damage or breakdown of ecosystems as consequences of water problems (Lehn and Parodi 2009).

Increasing pressure on water systems leads to competing claims for water usage and to corresponding conflicts. Insofar as these water conflicts refer to moral conflicts or normative uncertainties, ethical reasoning might help in better understanding and contribute to solving the conflict. Human values are present in these conflicts nonetheless, in the form of cultural or religious values based on traditions, or in the form of economic values in the Western approach of regarding water as a resource.

Human values are also present in water technologies or other intervention measures into water systems because technology is not value-free but inherently normative as can be learned by philosophy of technology (Grunwald 2013). The complex interplay between our normative views on water, water usage and water conflicts on the one hand, and normative aspects of water technology, on the other, need to be uncovered transparently in order to allow for an open and enlightened debate on our responsibility in this field.

Water conflicts arise in a different respect: as conflicts between today's generation and future generations, between users of water facing scarcity, in particular between upstream and downstream populations, between different types of usage (irrigation, industrial use, household use, etc.) and so forth. Ethics cannot identify "best solutions" in these conflicts and then force the conflict partners to accept. Ethics only can help to better understand the normative structure of water conflicts and support deliberation about responsible solutions. Ethics may contribute to a bottom-up process of conflict solving by conducting an ethical discourse with all groups involved - and which advocates for those who cannot participate directly such as future generations or ecosystems.

Ethically legitimate principles cover the most relevant concerns on water issues and transform them into guidance for such interventions into water systems, which are compatible to the imperative of sustainable development or even support this imperative. However, there is no direct way from these (or other) principles to specific recommendations in the case of a challenge at hand. Often, the principles must be weighed, balanced and prioritised - a complex challenge, which can be met only by carefully considering the individual case under consideration. Responsible solutions can be identified only in a genuine process of ethical deliberation involving persons, groups, representatives of moral positions and advocates of non-human (such as eco-systems) of future generations. The ethical discourse as a process of real deliberation and following legitimate rules is the place where ethical theory, water systems analysis, environmental sciences and engineering inter-disciplinarily meet with context-specific requirements and trans-disciplinarily with specific actors of the field.

The research project out of which this volume emerged focused on two specific water systems and the involved water conflicts: the Fergana Valley in Uzbekistan and the Lower Jordan Valley with Israel, Jordan and Palestine as involved regions. The 
results of the inter-disciplinary research and analysis are presented in the following chapters. They may be considered as first and knowledge-providing steps towards a "real deliberation" with people concerned and affected as well as with stakeholders and decision-makers.

Open Access This chapter is distributed under the terms of the Creative Commons Attribution Noncommercial License, which permits any noncommercial use, distribution, and reproduction in any medium, provided the original author(s) and source are credited.

\section{References}

Al-Awar F, Abdulrazzak M, Al-Weshah R (2010) Waters ethics perspectives in the Arab Region. In: Brown PG, Schmidt J (eds) Water ethics. Foundational readings for students and professionals. Island Press, Washington, DC, pp 29-38

Armstrong A (2006) Ethical issues in water use and sustainability. Area 38:9-15. doi:10.1111/j.1475-4762.2006.00657.x

Armstrong AC (2009) Viewpoint - further ideas towards a water ethic. Water Altern 2:138-147

Armstrong AC, Armstrong MB (2005) A Christian perspective on water and water rights. In: Tvedt $\mathrm{T}$, Oestigaard T (eds) A history of water: the world of water, 3rd edn. Tauris, London/New York, pp 367-384

Bartholomew I Ecumenical Patriarch of Constantinople (2010) Byzantine heritage. In: Brown P, Schmidt J (eds) Water ethics. Foundational readings for students and professionals. Island Press, Washington, DC, pp 25-28

Faruqui N, Biswas A, Bino M (2001) Water management in Islam. United Nations University Press, Tokyo

Gethmann CF, Sander T (1999) Rechtfertigungsdiskurse. In: Grunwald A, Saupe S (eds) Ethik in der Technikgestaltung. Praktische Relevanz und Legitimation. Springer, Berlin, pp 117-151

Gilli F (2004) Islam, water conservation and public awareness campaigns. Paper presented at the 2nd Israeli-Palestinian-international academic conference on water for life, Antalya, 10-14 October 2004

Groenfeldt D (2013) Towards a new water ethic. In: Bhaduri A, Flinkerbusch E, Holtermann T et al (eds) The Bonn declaration on global water security. Global Water System Project, Bonn, pp 14-15

Grunwald A (2007) Working towards sustainable development in the face of uncertainty and incomplete knowledge. J Environ Policy Plan 9:245-262. doi:10.1080/15239080701622774

Grunwald A (2013) Handbuch Technikethik. Metzler, Stuttgart

Grunwald A, Kopfmüller J (2012) Nachhaltigkeit, 2nd edn. Campus, Frankfurt am Main

Habermas J (1991) Erläuterungen zur Diskursethik. Suhrkamp, Frankfurt am Main

Habermas J (2008) Hat die Demokratie noch eine epistemische Dimension? Empirische Forschung und normative Theorie. In: Habermas J (ed) Ach, Europa. Suhrkamp, Frankfurt am Main, pp 138-191

Harremoës P (2002) Water ethics - a substitute for over-regulation of a scarce resource. Water Sci Technol 45:113-124

Harremoës P, Gee D, MacGarvin M (2002) The precautionary principle in the 20th century. Late lessons from early warnings. Sage, London

Jonas H (1979) Das Prinzip Verantwortung: Versuch einer Ethik für die technologisierte Zivilisation. Suhrkamp, Frankfurt am Main

Katz E (1997) Nature as subject: human obligation and natural community. Rowman \& Littlefield, Lanham 
Lehn H, Parodi O (2009) Wasser - elementare und strategische Ressource des 21. Jahrhunderts. Umweltwissenschaften und Schadstoffforschung 21:272-281. doi:10.1007/s12302-009-0052-6

Leopold A (1949) A sand county almanac, and sketches here and there. Oxford University Press, Oxford

McGee WJ (1909) Water as a resource. Ann Am Acad Polit Sci 33:37-50

McGee WJ (1911) Principles of water-power development. Science 34:813-825. doi:10.1126/ science.34.885.813

Nida-Rümelin J (2005) Angewandte Ethik. Die Bereichsethik und ihre theoretische Fundierung. Metzler, Stuttgart

Ostrom E, Stern PC, Dietz T (2003) Water rights and the commons. In: Brown P, Schmidt J (eds) Water ethics. Foundational readings for students and professionals. Island Press, Washington, DC, pp 147-154

Ott K (2010) Umweltethik zur Einführung. Junius, Hamburg

Parodi O (2008) Technik am Fluss. Philosophische und kulturwissenschaftliche Betrachtungen. Oekom verlag, München

Postel S (2010) The missing piece: a water ethic. In: Brown P, Schmidt J (eds) Water ethics. Foundational readings for students and professionals. Island Press, Washington, DC, pp 221-226

Potthast T (2013) Geo- und Hydrotechnik sowie Bergbau. In: Grunwald A (ed) Handbuch Technikethik. Metzler, Stuttgart, pp 284-289

Pradhan R, Meinzen-Dick RS (2010) Which rights are right? Water rights, culture, and underlying values. In: Brown P, Schmidt J (eds) Water ethics. Foundational readings for students and professionals. Island Press, Washington, DC, pp 39-58

Priscoli Delli J, Dooge J, LLamas R (2004) Water and ethics: overview. http://www.internationalwaterlaw.org/bibliography/articles/Ethics/Overview.pdf. Accessed 28 Jan 2015

Renn O, Webler T (1998) Der kooperative Diskurs - Theoretische Grundlagen, Anforderungen, Möglichkeiten. In: Wilhelm U (ed) Abfallpolitik im kooperativen Diskurs. Bürgerbeteiligung bei der Standortsuche für eine Deponie im Kanton Aargau. ETH Zürich, Zürich, pp 3-103

Schmidt JJ, Shrubsole D (2013) Modern water ethics: implications for shared governance. Environ Values 22:329-379. doi:10.3197/096327113X13648087563746

Schwemmer O (1987) Handlung und Struktur. Suhrkamp, Frankfurt am Main

Trawick P (2010) Encounters with the moral economy of water: general principles for successfully managing the commons. In: Brown P, Schmidt J (eds) Water ethics. Foundational readings for students and professionals. Island Press, Washington, DC, pp 155-165

UNESCO (2011) Water ethics and water resource management. http://unesdoc.unesco.org/ images/0019/001922/192256e.pdf. Accessed 28 Jan 2015

WCED (1987) Report of the World Commission on Environment and Development: our common future. http://www.un-documents.net/our-common-future.pdf. Accessed 28 Jan 2015

Young GJ, Dooge JC, Rodda JC (1994) Global water resources issues. Cambridge University Press, Cambridge 